\title{
GEOINDICADORES APLICADOS AL ESTUDIO DE IMPACTOS AMBIENTALES EN EL ÁREA PERIURBANA DE LA CIUDAD DE CORRIENTES.
}

\section{APPLIED GEOINDICATORS TO THE STUDY OF ENVIRONMENTAL IMPACTS IN "BORDER TERRITORY” OF CORRIENTES CITY}

\author{
Arq. Silvina López, Ing. Guillermo Antonio Arce y \\ Prof. Mg. Jorge Alfredo Alberto \\ Centro de Geociencias Aplicadas Facultad de \\ Humanidades - Facultad de Ingeniería \\ Universidad Nacional del Nordeste - UNNE \\ E-mail: jaalberto@hotmail.com
}

\section{Resumen}

El periurbano constituye un "territorio de borde" que está sometido a procesos económicos relacionados con la valorización capitalista del espacio, como consecuencia de la incorporación de nuevas tierras a la ciudad. La ocupación del suelo generalmente se realiza de una manera no planificada, constituyendo un espacio de gran heterogeneidad, donde pueden registrarse problemáticas sociales y ambientales agudas.

Corrientes, está experimentando en los últimos años la localización de proyectos inmobiliarios con el formato de urbanizaciones cerradas en las áreas periurbanas del municipio y de los municipios vecinos de Santa Ana, San Cayetano y Riachuelo. Este tipo de inversiones inmobiliarias, destinadas a satisfacer la demanda de vivienda de familias de ingresos medianos y altos, se apropia de tierras con renta agrícola para obtener renta urbana, produciendo la modificación del área periurbana productiva, generando impacto ambiental, e iniciando un proceso de segregación residencial.

Palabras claves: indicadores, crecimiento urbano, impactos ambientales, territorio de borde.

\begin{abstract}
:
The area located between the urban and rural space constitutes a "border territory" that is subjected to economic processes related to the capitalist valorization of the land, as consequence of the incorporation of new lands to the city. The land use is usually performed in an unplanned way, resulting in an area of great heterogeneity, where it can be found important social and environmental problems.

In the last years, Corrientes city has experienced the localization of real estate projects in the form of gated communities in its periphery area and this also has happened in neighbor municipalities of Santa Ana, San Cayetano and Riachuelo. This kind of real estate investments, dedicated to satisfy the demand of housing of families of middle and upper income, appropriates the lands with agricultural rent to obtain urban rent, resulting in the modification of the productive area, creating environmental impact and initiating a process of residential segregation.
\end{abstract}

Keywords: indicators, urban growth, environmental impacts, border territory.

Publicado en formato digital: Arq. Silvina López, Ing. Guillermo Antonio Arce y Prof. Mg. Jorge Alfredo Alberto. GEOINDICADORES APLICADOS AL ESTUDIO DE IMPACTOS AMBIENTALES EN EL ÁREA PERIURBANA DE LA CIUDAD DE CORRIENTES. Revista Geográfica Digital. IGUNNE. Facultad de Humanidades. UNNE. Año 2015. N No 23. Enero - Junio 2015. ISSN 1668-5180 Resistencia, Chaco.

En: http://hum.unne.edu.ar/revistas/geoweb/default.htm 


\section{Introducción}

Este trabajo se enmarca dentro de un proyecto mayor que se desarrolla en el Centro de Geociencias Aplicadas (Humanidades -Ingeniería, UNNE) referido a la aplicación de geoindicadores a los distintos aspectos de la problemática ambiental del territorio, y que toma como objeto de estudio a los centros urbanos del Gran Resistencia y el Gran Corrientes y los ámbitos periurbanos próximos. En este marco y en el proceso de construcción de los geoindicadores, se analiza el fenómeno en el área periurbana de Corrientes y Santa Ana de los Guácaras.

Los geoindicadores, pueden ser aplicados tanto en fenómenos específicos con comportamientos cíclicos sobre la superficie terrestre en largos periodos de tiempo para determinar cambios en el paisaje, como en espacios con dinámicas complejas en su evolución en cortos periodos de tiempo, como es el caso de la dinámica y evolución del crecimiento urbano y su incidencia sobre entornos rurales (Alberto, J. 2012). Es decir, pueden ayudar a determinar problemáticas e impactos ambientales, monitorear ecosistemas, cambios en el uso del suelo, seleccionar prácticas de manejo y determinar condiciones de base previas a todo proyecto de desarrollo urbano (Coltrinari, L. 2001).

Por otra parte, los indicadores como variables que vuelven visibles o perceptibles fenómenos de interés, y miden y comunican información relevante, deben representar atributos considerados importantes por los tomadores de decisión y/o la población, para aportar a los procesos de toma de decisiones sobre el territorio (Gallopín, 2006).

El proceso de ocupación del espacio se analiza bajo el concepto de marco causal, que se basa en el principio de causalidad (Presión - Estado - Respuesta), es decir que las actividades humanas ejercen presión sobre el ambiente y cambian las características cualitativas y cuantitativas de los recursos. Este marco conceptual, muy utilizado debido a su simpleza y a la posibilidad de aplicación a diferentes niveles y escalas, fue desarrollado por la Organización para la Cooperación y el Desarrollo Económicos (OCDE, 1991; 1993) a partir del modelo original de Presión-Respuesta de Friends y Raport. Posteriormente las Naciones Unidas reemplazó el término "presión" por "impulso", para extender la dimensión ecológica a los indicadores sociales, económicos e institucionales.

El análisis que se realiza en ese trabajo se centra en el espacio periurbano, un área de gran heterogeneidad y crecimiento acelerado, donde pueden registrarse problemáticas sociales y ambientales agudas, un mercado del suelo poco transparente y proximidades conflictivas (Puebla, 2004: 5). Este territorio de borde está sometido a procesos económicos relacionados con la valorización capitalista del espacio, como consecuencia de la incorporación real o potencial de tierras a la ciudad.

Según Capel, en pocas partes de la superficie terrestre existen espacios que tengan tal diversidad y mezcla de usos del suelo, y donde el medio natural esté sometido a tan intensas presiones. La eliminación del suelo agrícola es una de las formas más dramáticas de intervención social. (Capel, 1994: 139-140).

A nivel espacial, los procesos de fragmentación social propios de la cultura postmoderna y el capitalismo global, se reflejan de acuerdo con Buzai, en el modelo de la ciudad fragmentada. Una de las manifestaciones de este proceso se verifica en el desplazamiento de los grupos de alto nivel socio- económico hacia áreas suburbanas cerradas y aisladas de la trama urbana tradicional de la ciudad. (Buzai, 2003: 96-102).

Esta nueva localización de la elite según Janoschka es la que está dando forma a las ciudades latinoamericanas en el siglo XXI, en donde las urbanizaciones privadas son mucho más que un fenómeno de naturaleza arquitectónica, son una manifestación de la polarización social en sociedades que se han desprendido rápidamente de las características organizativas del "estado de bienestar". Según este autor, "las urbanizaciones privadas son la expresión extrema de una forma de

Publicado en formato digital: Arq. Silvina López; Ing. Guillermo Antonio Arce; Prof. Mgter. Jorge Alfredo Alberto. GEOINDICADORES APLICADOS AL ESTUDIO DE IMPACTOS AMBIENTALES EN EL ÁREA PERIURBANA DE LA CIUDAD DE CORRIENTES. Revista Geográfica Digital. IGUNNE. Facultad de Humanidades. UNNE. Año 12. N No 23. Enero - Junio 2015. ISSN 1668 - 5180. Resistencia, Chaco. En: http://hum.unne.edu.ar/revistas/geoweb/default.htm 
segregación social voluntaria que se da en países subdesarrollados y sociedades muy polarizadas que carecen de un Estado social fuerte" (Janoschka, 2002: 310). El nuevo modelo de ciudad latinoamericana representa una distancia importante con la ciudad tradicional, que estaba conformada sobre todo, por la integración de espacios diferentes, y constituida por espacios públicos y abiertos (Janoschka, 2002: 315).

En la Argentina, los primeros emprendimientos de "club de campo" nacieron en la década del '60 orientados a la demanda de viviendas de fin de semana, pero a principios de la década del ' 90 , con las mejoras en las comunicaciones se convirtió en vivienda permanente, dando origen al barrio privado. Este producto inmobiliario se expandió hacia todo el país, con mayor desarrollo en las grandes ciudades.

Algunos autores sostienen que la principal justificación para la proliferación de barrios cerrados es el desplazamiento de las clases altas del centro de la ciudad buscando formas más seguras de residencia (Caldeira, 2000: 254), sin embargo otros sostienen que los principales motivos están relacionados con la relación precio-calidad de la vivienda y el acceso a bienes que de manera individual son difíciles de conseguir, como amenidades ambientales, instalaciones deportivas, educativas y de seguridad. (Sabatini y Cáceres, 2004: 19). Los barrios cerrados simbolizan un nuevo estilo de vida asociado a propiedades aisladas, "Ios enclaves fortificados confieren estatus, la construcción de símbolos de estatus es un proceso que profundiza las diferencias sociales y crea los medios para la afirmación de la distancia social y la desigualdad" (Caldeira, 2000: 258).

Junto a la segregación social, emergen la fragmentación del espacio urbano, favorecida con la creación de estos enclaves residenciales de clase alta en un entorno de nivel socioeconómico más bajo, y la privatización de las calles y de otros espacios públicos, que lleva a sus residentes a disminuir la interacción social en la ciudad (Solinis, 2002: 21-23).

Por otra parte, Sabatini considera que la segregación residencial es un fenómeno, no un problema, y que sus efectos están directamente relacionados con la escala geográfica en que esta ocurre, y con las fases de evolución, ya que la segregación residencial es un proceso no una situación, es un fenómeno que tiene causas y, posiblemente, fases de evolución más o menos predecibles (Sabatini, 2003: 8).

En cuanto al rol del Estado en el proceso de configuración de estos fenómenos, el escenario de las políticas públicas es un espacio de disputa de actores que se movilizan según intereses, en pos de incidir en el proceso a través de la utilización de todo tipo de recursos, en donde el Estado asume un rol protagónico por su poder de legitimación de las decisiones (Subirats, 2001: 259-264). En este sentido, las políticas públicas son herramientas del Estado para la conformación, regulación y legitimación de grupos sociales y, al mismo tiempo como acciones, generan transformaciones en la realidad social conducentes al cambio o al mantenimiento del orden establecido (Jobert, 2004).

El análisis de la política y sus instrumentos normativos permite visibilizar como el Estado interviene en la problemática, entendiendo que la política territorial no es neutral respecto del modelo de desarrollo de la sociedad.

\section{El fenómeno en Corrientes}

Corrientes, capital de la provincia, es una ciudad media en la que predominan las actividades vinculadas con la prestación de servicios a escala de la ciudad y de un entorno regional, con importante participación económica de la administración pública y los servicios sociales (Identificada como "Nodo Regional" en el Plan Estratégico Territorial 2011). Un poco más del 20\% del territorio del Municipio Capital (cuyo ejido municipal es de 27.960 has.) corresponde a la ciudad de Corrientes, mientras el resto corresponde a áreas periurbana y rural.

Publicado en formato digital: Arq. Silvina López; Ing. Guillermo Antonio Arce; Prof. Mgter. Jorge Alfredo Alberto. GEOINDICADORES APLICADOS AL ESTUDIO DE IMPACTOS AMBIENTALES EN EL ÁREA PERIURBANA DE LA CIUDAD DE CORRIENTES. Revista Geográfica Digital. IGUNNE. Facultad de Humanidades. UNNE. Año 12. No 23. Enero - Junio 2015. ISSN 1668 - 5180. Resistencia, Chaco. En: http://hum.unne.edu.ar/revistas/geoweb/default.htm 
Revista Geográfica Digital. IGUNNE. Facultad de Humanidades. UNNE. Año 12. № 23. Enero - Junio 2015. ISSN 1668-5180 Resistencia, Chaco

La ciudad tiene una población de 358.223 hab. (Censo Nacional de Población, Hogares y Vivienda, Argentina 2010), con muy baja densidad promedio (55,5 hab/ha), y muy bajo nivel de consolidación de infraestructuras, equipamientos y servicios.

Con un tipo de expansión discontinua y periférica, en los últimos años se está acelerando el proceso de localización de desarrollos residenciales en las áreas periurbanas próximas, siendo la de mayor importancia por cantidad y tamaño de los proyectos, la de vinculación con Santa Ana de los Guácaras.

Santa Ana, ubicada a $15 \mathrm{~km}$, fue el primer núcleo de expansión territorial de la ciudad de Corrientes, y surgió como un caserío disperso donde los indios Guácaras trabajaban en sus chacras para autoabastecimiento. A fines del 1800 se inició un período de desarrollo con la instalación del Ingenio Primer Correntino y luego del Ferrocarril Económico, que transportaba materia prima y leña, y luego la producción elaborada hacia el puerto y los mercados. En las colonias se producía caña de azúcar de manera intensiva para el abastecimiento de la industria. En 1949 el ingenio entró en crisis y se transformó en industria de destilación y bebidas alcohólicas hasta su cierre. Por su parte, el ferrocarril continuó funcionando hasta 1968. (Sanchez Negrette, 1995).

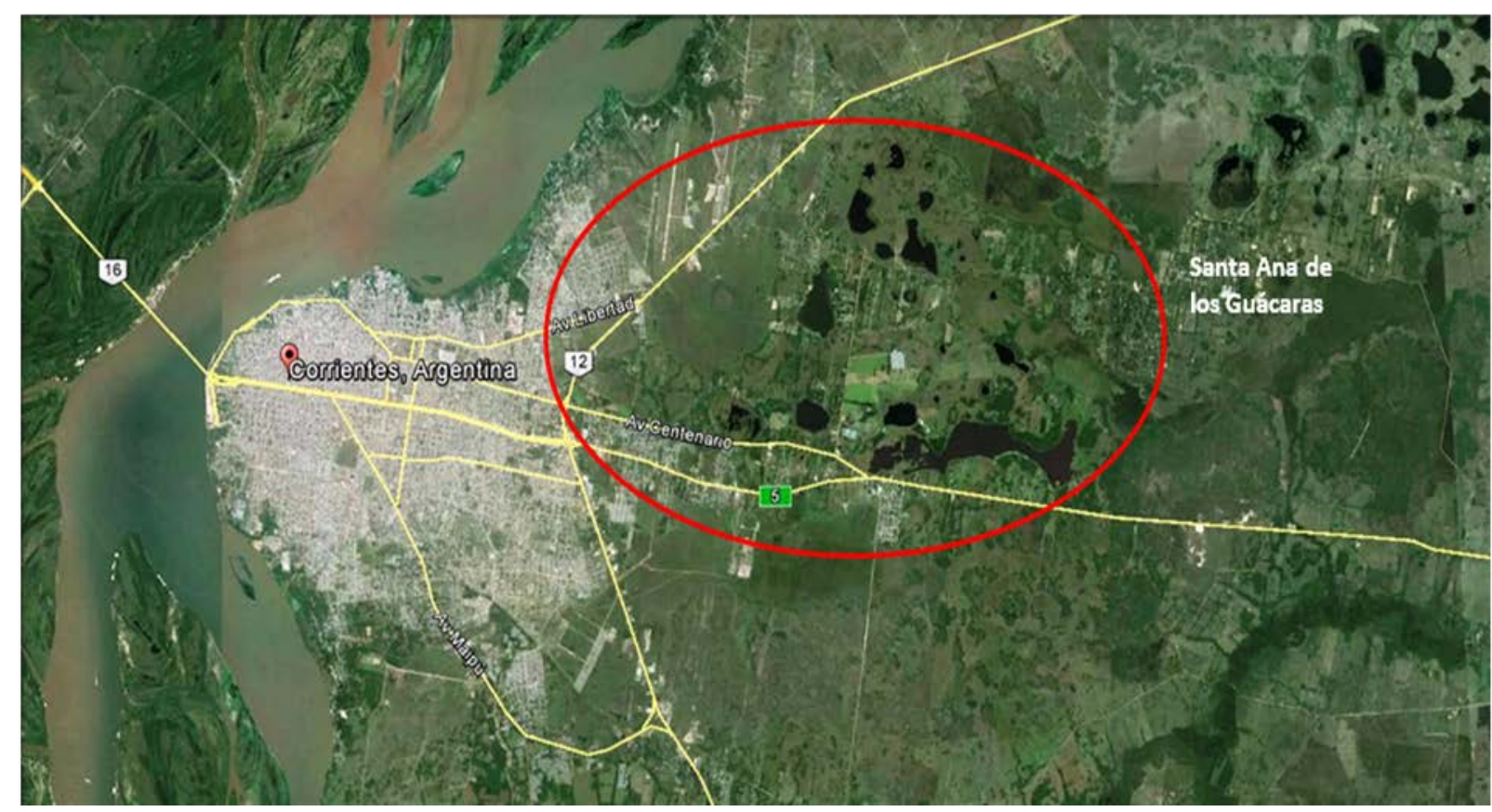

Fig. 1: Localización del área de análisis. Área periurbana y rural de Corrientes y Santa Ana

En los años 80 y 90, diversos emprendimientos productivos se asentaron en el área de vinculación entre Corrientes y Santa Ana, la mayoría sobre la RP No 43 de acceso a la localidad (avícola, frigorífico de aves, cría de faisanes, codornices, yacaré, búfalos, etc.), debido a la localización estratégica con respecto a las ciudades de Corrientes y Resistencia. También a partir de los '80 se empezaron a localizar clubes, emprendimientos turísticos sobre la laguna Soto, y las primeras urbanizaciones residenciales cerradas.

Actualmente, Santa Ana es una localidad rural de 1906 hab. (Censo Nacional de Población, Hogares y Vivienda, Argentina 2010), que se destaca por su gran valor patrimonial, histórico y turístico, por el que en el año 1976 fue declarada pueblo de Interés Histórico-Turístico (Ley № 3327). GEOINDICADORES APLICADOS AL ESTUDIO DE IMPACTOS AMBIENTALES EN EL ÁREA PERIURBANA DE LA CIUDAD DE CORRIENTES. Revista Geográfica Digital. IGUNNE. Facultad de Humanidades. UNNE. Año 12. N No 23. Enero - Junio 2015. ISSN 1668 - 5180. Resistencia, Chaco. En: http://hum.unne.edu.ar/revistas/geoweb/default.htm 
Revista Geográfica Digital. IGUNNE. Facultad de Humanidades. UNNE. Año 12. № 23. Enero - Junio 2015. ISSN 1668-5180 Resistencia, Chaco

En el territorio del Municipio predominan las casas quintas con vivienda y chacras con producción de autoconsumo y en los predios de mayor superficie, la ganadería bovina extensiva es la actividad más importante. Según datos del INTA Corrientes, en 2003 el 52\% de los predios rurales eran casas quinta con vivienda y el $40 \%$ tenían una superficie menor a 2 has.

\section{Posibles causas y evolución}

El que se analiza es un proceso en evolución, que se inició con urbanizaciones de una escala geográfica relativamente reducida, localizadas sobre la RP No43, y luego se extendió a la RP 99, que permite la conexión con Corrientes por el acceso Oeste.

En los últimos años, se ha incrementado tanto el número de emprendimientos inmobiliarios como el tamaño de los mismos. Se trata de urbanizaciones residenciales con equipamiento deportivo y recreativo, no así equipamiento educativo, ni paseos comerciales u oficinas, como en casos analizados en otras ciudades del país. El tamaño de los desarrollos relevados varía entre 11 y más de 50 has, con lotes entre 1.000 y $9.000 \mathrm{~m}^{2}$.

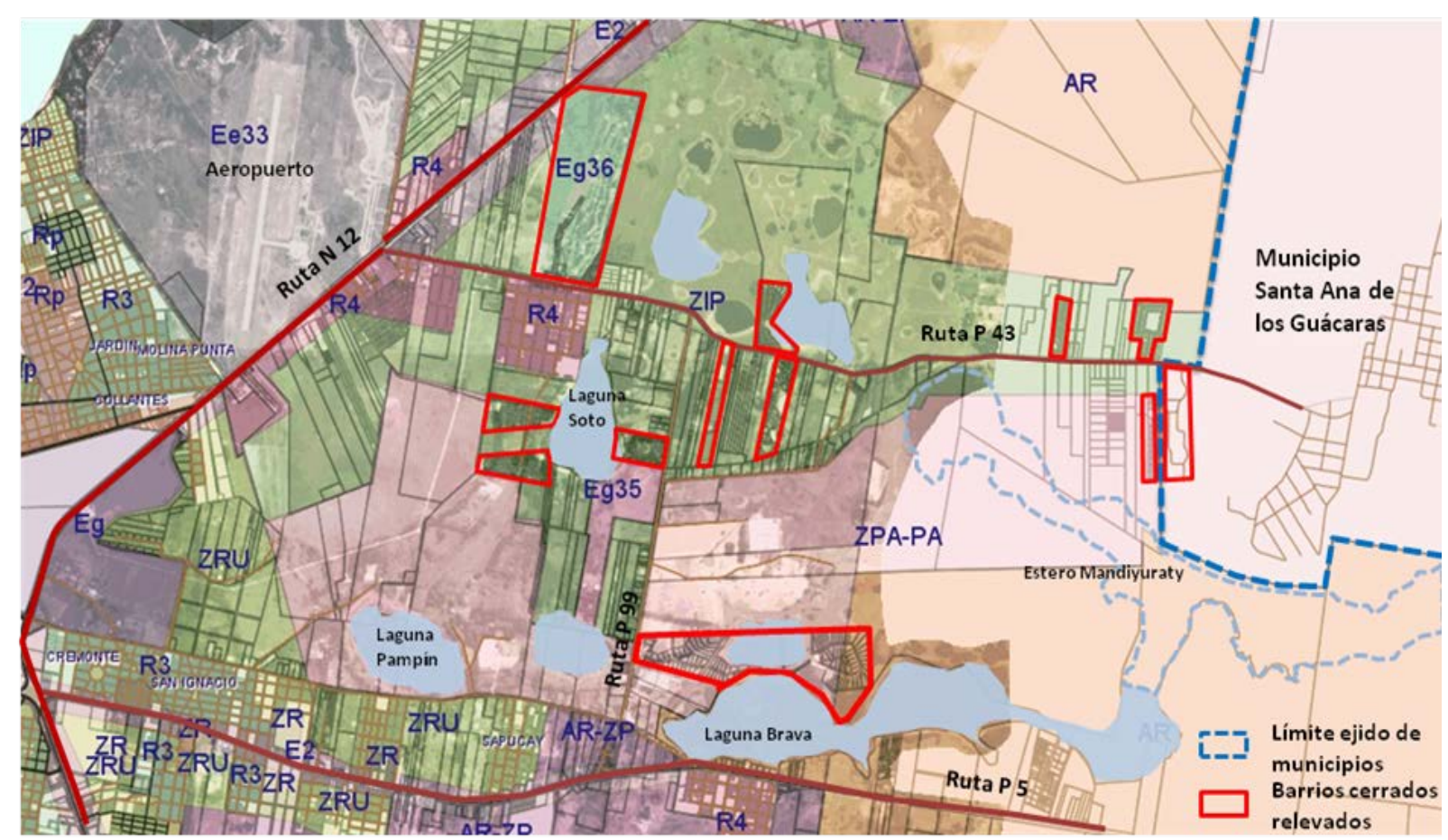

Zonas del Área Rural. Código de Planeamiento Urbano de la Ciudad de Ctes. Ord. № 1071 y modificatorias AR-ZP: Área rural-Zona de Protección, ZPA-PA: Zona de promoción agropecuaria y Protección ambiental, ZIP: Zona de Interés paisajistico, R4: Distrito residencial extra urbano, E2, Eg, Ee: Distritos de equipamientos

Fig. 2: Barrios cerrados relevados en el área periurbana de Corrientes y Santa Ana. Fuente: Elaboración propia con base en SIG de la Municipalidad de Corrientes y publicaciones de Inmobiliarias

Publicado en formato digital: Arq. Silvina López; Ing. Guillermo Antonio Arce; Prof. Mgter. Jorge Alfredo Alberto. GEOINDICADORES APLICADOS AL ESTUDIO DE IMPACTOS AMBIENTALES EN EL ÁREA PERIURBANA DE LA CIUDAD DE CORRIENTES. Revista Geográfica Digital. IGUNNE. Facultad de Humanidades. UNNE. Año 12. N No 23. Enero - Junio 2015. ISSN 1668 - 5180. Resistencia, Chaco. En: http://hum.unne.edu.ar/revistas/geoweb/default.htm 
En relación con las causas que pueden generar este fenómeno, con la información disponible, se pueden identificar dos cuestiones:

- La primera, en la ciudad de Corrientes es escasa la oferta de suelo con infraestructuras y equipamientos, lo que impacta en altísimos valores de los inmuebles en la zona céntrica de la ciudad y en los barrios de mayor calidad urbana. El valor actual de la tierra en los proyectos inmobiliarios se encuentra por debajo de estos valores, se puede equiparar a los precios en barrios más periféricos de la ciudad, de baja calidad urbana y problemas de conectividad con la centralidad (a diciembre de 2013, Club de Campo Don Manuel lotes de 1.019 a $2.309 \mathrm{~m}^{2}$ entre \$ 195.000 y \$235.000; Club de campo Santa Bárbara lotes de 1000 a $1800 \mathrm{~m}^{2}$ desde $\$$ 190.000; lote urbano de $300 \mathrm{~m}^{2}$ superaba los $\$ 300.000$.).

En este sentido, la valorización de la propiedad inmueble como negocio para los inmobiliarios y como patrimonio para las familias, es una fuerte motivación para el desarrollo de estos proyectos. Evidentemente es un buen negocio que transforma tierra de valor rural en tierra de valor urbano.

- La segunda, las expectativas de calidad de vida, la búsqueda de condiciones a las que difícilmente se accede en la ciudad o de forma individual, como equipamiento social y deportivo, monitoreo continuo las $24 \mathrm{hs}$, y hasta el uso privado de lagunas y de paisajes naturales.

Aparentemente en este caso, además de motivaciones sociales que llevan a la auto segregación de las elites y grupos emergentes planteadas por los autores analizados, el fenómeno es más bien el resultado del funcionamiento del mercado inmobiliario, ya que la valorización inmobiliaria tiene una influencia preponderante en el proceso de segregación.

\section{Los efectos e impactos; estado resultante en el ambiente evaluado}

Sin lugar a dudas el fenómeno que se analiza está modificando paulatinamente la conformación del espacio periurbano y rural, y provocando diversos impactos. Se trata de un área con suelos de muy buena aptitud agrícola en los que se desarrollan actividades productivas que dan trabajo a la población local gran parte del año, por lo que evidentemente la disminución o desaparición de las mismas impacta en la economía local. Por otra parte, la mezcla en los usos del suelo, entre los sistemas productivos tradicionales, con viviendas e instalaciones destinadas al ocio, pueden producir problemas de convivencia entre vecinos. Los primeros generan olores nauseabundos, animales sueltos, etc., en tanto los segundos provocan elevados niveles de ruido y movimiento de personas y vehículos, muy diferentes a los usuales en la localidad.

Publicado en formato digital: Arq. Silvina López; Ing. Guillermo Antonio Arce; Prof. Mgter. Jorge Alfredo Alberto. GEOINDICADORES APLICADOS AL ESTUDIO DE IMPACTOS AMBIENTALES EN EL ÁREA PERIURBANA DE LA CIUDAD DE CORRIENTES. Revista Geográfica Digital. IGUNNE. Facultad de Humanidades. UNNE. Año 12. No 23. Enero - Junio 2015. ISSN 1668 - 5180. Resistencia, Chaco. En: http://hum.unne.edu.ar/revistas/geoweb/default.htm 
Revista Geográfica Digital. IGUNNE. Facultad de Humanidades. UNNE. Año 12. № 23. Enero - Junio 2015. ISSN 1668-5180 Resistencia, Chaco

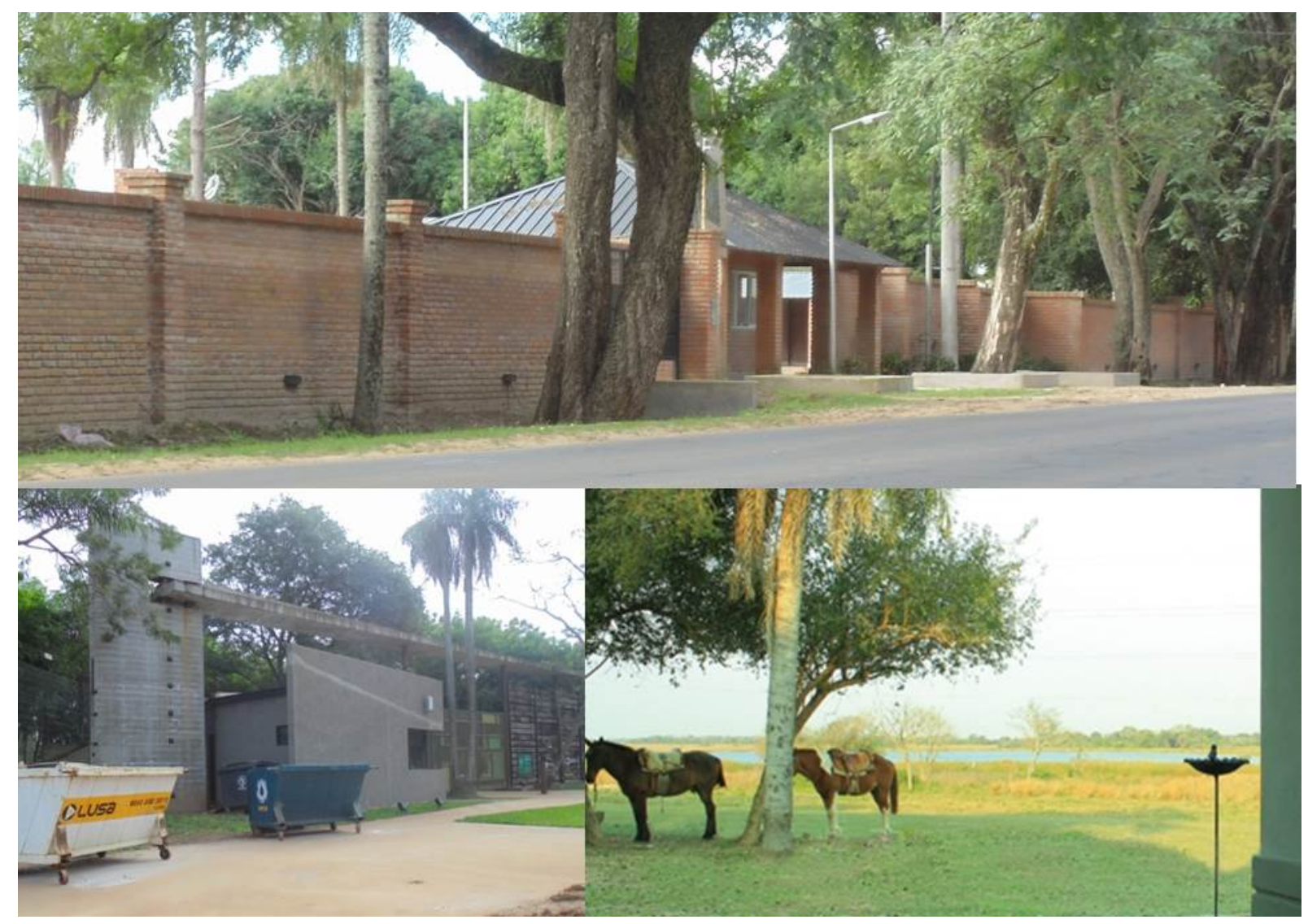

Fig. 3: Imágenes de barrios cerrados localizados sobre Ruta Provincial $n^{\circ} 43$ y Ruta Provincial $n^{\circ} 99$

En cuanto a los impactos ambientales, la pérdida de las áreas de cobertura vegetal profundiza la erosión e intensifica las obstrucciones de canales y desagües, dando lugar a la acumulación de sedimentos en las depresiones y al aumento de las zonas inundadas, con pérdida de la capa fértil del suelo. La construcción de accesos, canalizaciones y nivelación para los barrios cerrados, está produciendo obstaculización del escurrimiento natural y modificación de niveles; la ausencia de red cloacal está provocando la contaminación de espejos de agua y napas; y los residuos domiciliarios sin un sistema eficiente de recolección y disposición final generando minibasurales. Se están verificando además, problemas de transporte y tránsito, por la sobrecarga de flujo vehicular de las rutas de conexión con Corrientes, que no han sido adaptadas a los requerimientos actuales.

Publicado en formato digital: Arq. Silvina López; Ing. Guillermo Antonio Arce; Prof. Mgter. Jorge Alfredo Alberto. GEOINDICADORES APLICADOS AL ESTUDIO DE IMPACTOS AMBIENTALES EN EL ÁREA PERIURBANA DE LA CIUDAD DE CORRIENTES. Revista Geográfica Digital. IGUNNE. Facultad de Humanidades. UNNE. Año 12. No 23. Enero - Junio 2015. ISSN 1668 - 5180. Resistencia, Chaco. En: http://hum.unne.edu.ar/revistas/geoweb/default.htm 
Revista Geográfica Digital. IGUNNE. Facultad de Humanidades. UNNE. Año 12. № 23. Enero - Junio 2015. ISSN 1668-5180 Resistencia, Chaco

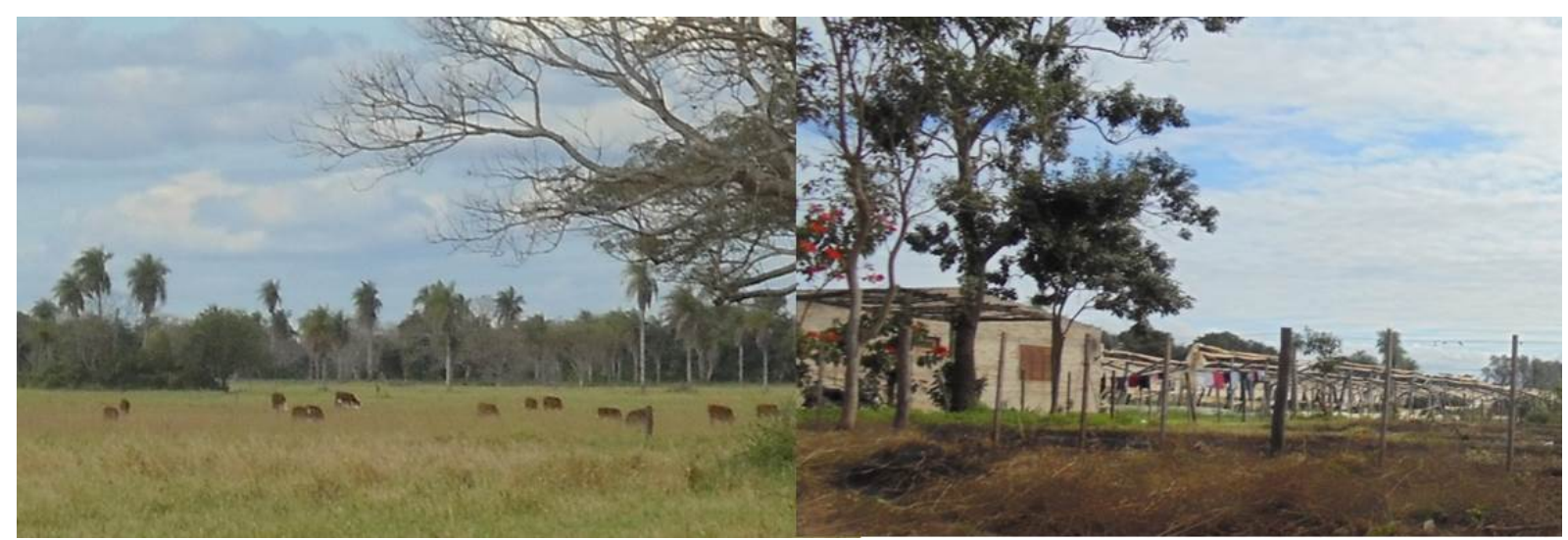

Fig. 4: Imágenes de predios rurales con producción ganadera y hortícola sobre Ruta Provincial nº 99.

En relación con el eje de análisis, lo que inicialmente eran vecindarios socialmente homogéneos de pequeña escala, donde los efectos negativos de la segregación pueden ser menores, se está transformando por agregación de desarrollos en ejecución y proyectos en proceso. Si la tendencia se mantiene y la segregación se intensifica, restringiéndose cada vez más las posibilidades de interacción física entre los grupos sociales, la segregación espacial será cada vez más negativa.

Se evidencian además, los emergentes de la segregación espacial que plantea Solinis: la fragmentación del espacio que se produce con estos enclaves residenciales en un entorno de nivel socioeconómico más bajo, y la privatización de los espacios públicos.
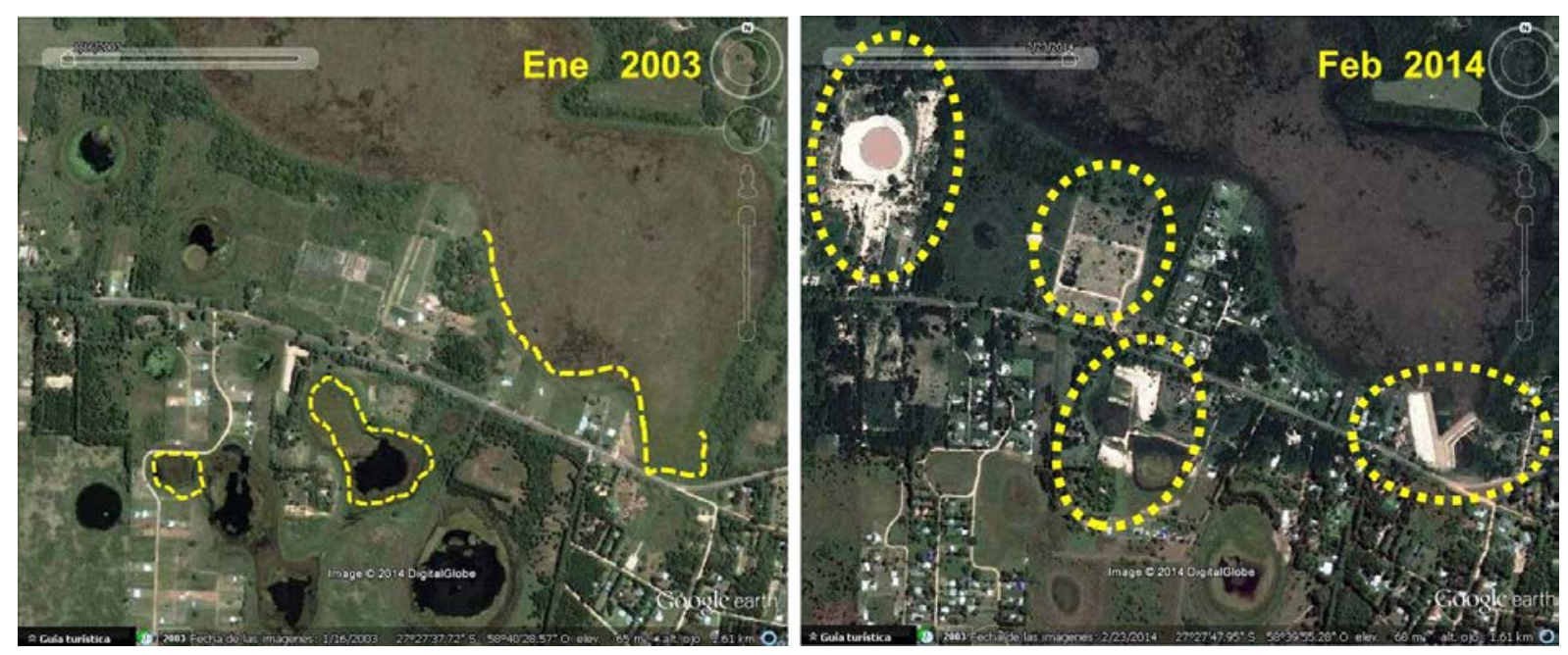

Fig. 5: Restricción al acceso a cuerpos de agua y relleno de sistemas lagunares.

Publicado en formato digital: Arq. Silvina López; Ing. Guillermo Antonio Arce; Prof. Mgter. Jorge Alfredo Alberto. GEOINDICADORES APLICADOS AL ESTUDIO DE IMPACTOS AMBIENTALES EN EL ÁREA PERIURBANA DE LA CIUDAD DE CORRIENTES. Revista Geográfica Digital. IGUNNE. Facultad de Humanidades. UNNE. Año 12. No 23. Enero - Junio 2015. ISSN 1668 - 5180. Resistencia, Chaco. En: http://hum.unne.edu.ar/revistas/geoweb/default.htm 
Revista Geográfica Digital. IGUNNE. Facultad de Humanidades. UNNE. Año 12. № 23. Enero - Junio 2015. ISSN 1668-5180 Resistencia, Chaco

En este caso se están produciendo además, situaciones de limitación del acceso de la población a bienes públicos, ya que en las urbanizaciones cerradas quedan incluidos espejos de agua y otras áreas naturales del sistema hídrico, y además en muchos casos, la localización de estas urbanizaciones genera discontinuidad en la circulación y conexión de caminos rurales que anteriormente permitían el acceso a las mismas (Fig. 5). Estos nuevos proyectos realizan nivelaciones y rellenos que modifican las pendientes naturales y ejecutan obras hidráulicas de desagüe, sin atención las condiciones hidrológicas naturales de la cuenca (sistema lagunar y de humedales) y sin una visión de manejo integrado de la cuenca hídrica. Estas intervenciones tienen un fuerte impacto en la población más vulnerable que sufre las consecuencias de inundaciones pluviales en un sistema cada vez más antropizado y cuyo funcionamiento hidrológico ha sido alterado. (Fig. 6)

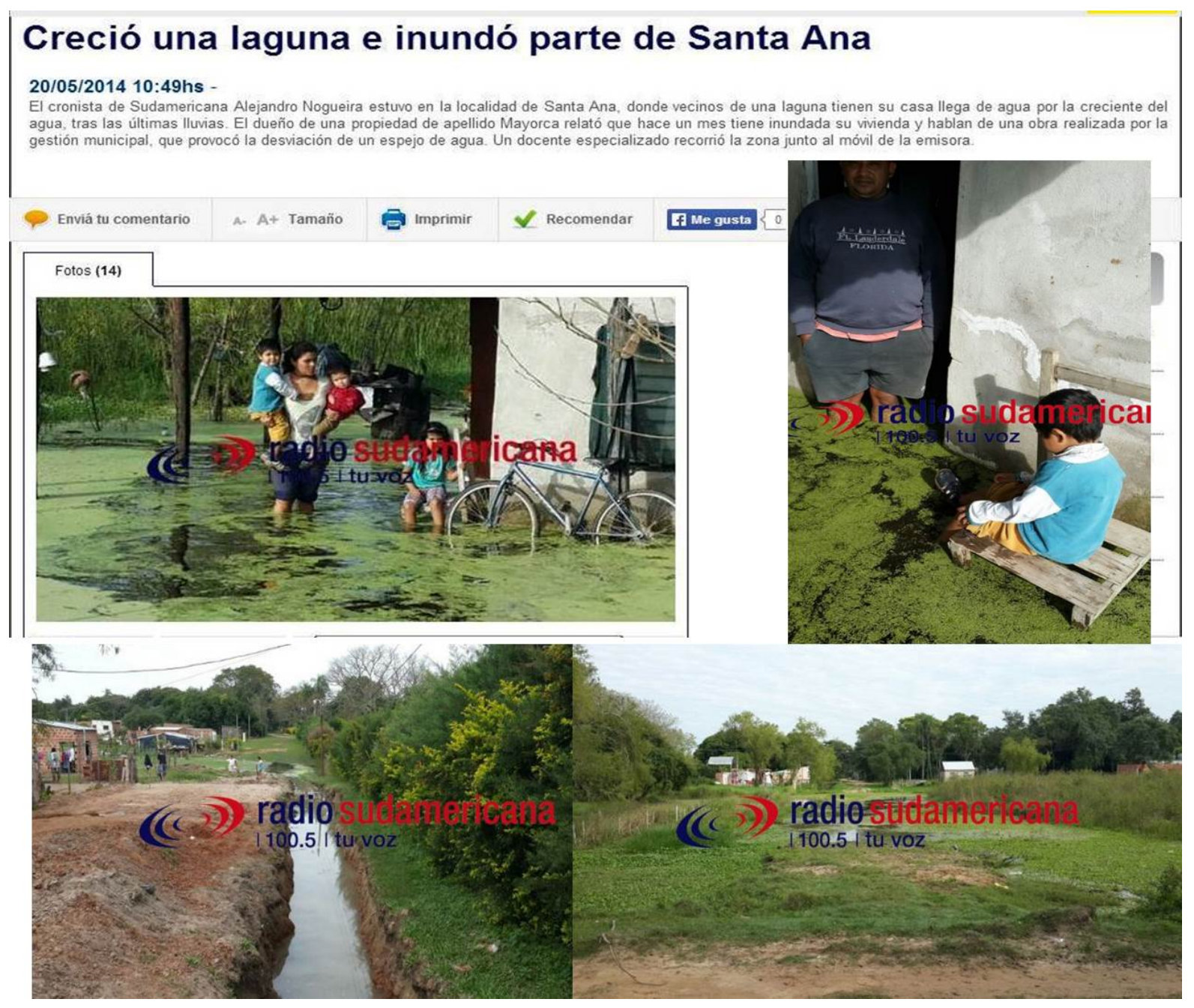

Fig. 6: Modificación de perfiles, canalizaciones y cambio de condiciones de escurrimiento

Publicado en formato digital: Arq. Silvina López; Ing. Guillermo Antonio Arce; Prof. Mgter. Jorge Alfredo Alberto. GEOINDICADORES APLICADOS AL ESTUDIO DE IMPACTOS AMBIENTALES EN EL ÁREA PERIURBANA DE LA CIUDAD DE CORRIENTES. Revista Geográfica Digital. IGUNNE. Facultad de Humanidades. UNNE. Año 12. N N $^{\circ}$ 23. Enero - Junio 2015. ISSN 1668 - 5180. Resistencia, Chaco. En: http://hum.unne.edu.ar/revistas/geoweb/default.htm 
Revista Geográfica Digital. IGUNNE. Facultad de Humanidades. UNNE. Año 12. № 23. Enero - Junio 2015. ISSN 1668-5180 Resistencia, Chaco

\section{La intervención del Estado en la regulación}

Tanto la Constitución de la Provincia de Corrientes como la Ley orgánica municipal, establecen las competencias de los niveles jurisdiccionales del Estado en la planificación del territorio. La Constitución establece en el "Art. 62: La Provincia y los municipios, en el marco de sus respectivas competencias, ordenan el uso del suelo y regulan el desarrollo urbano, suburbano y rural, bajo las siguientes pautas: 1) La utilización del suelo no puede afectar el interés general....(.....) , 4) El cumplimiento de los fines sociales de la actividad urbanística mediante la intervención en el mercado de tierras y la captación del incremento del valor agregado por planes u obras del Estado..."

Dadas las características ambientales del área de estudio, aparecen además, competencias provinciales en materia de gestión de los recursos naturales y el ambiente. La Constitución provincial (Constitución de la Provincia de Corrientes. Reforma 2007) establece en su Art 58 el dominio público sobre los recursos naturales. El Instituto Correntino del Agua y el Ambiente (ICAA), es el organismo autárquico del Estado Provincial que regula Recursos Hídricos, Gestión Ambiental, Tierras e Islas Fiscales y Minería, y es la autoridad de aplicación de la normativa ambiental, del Código de aguas (Decreto Ley $\mathrm{N}^{\circ} 191$, en el Art. 11 declara a todas las aguas de interés general y dominio público), y de la Ley de línea de ribera (Ley Provincial № 5588, Línea de Ribera). El ICAA tiene la atribución de determinar la cota que define la línea que separa un curso de agua de las propiedades ribereñas, constituyendo el límite jurídico entre el dominio público y privado.

También la figura de " barrio cerrado", está regulada por normativa provincial (Ley № 5405), que la define en el Art. $1^{\circ}$ : "Club de campo, Country, Complejo recreativo- residencial, Conjunto integral para residencias permanentes o de fin de semana, (...) jurisdicción territorial de extensión limitada que reúna los siguientes requisitos básicos: a) Que esté localizado en área urbana de expansión, subrural o rural, o en zonas especialmente afectadas a estos usos por los Municipios., b) Que cuente con un sector equipado para la práctica deportiva, social o cultural, con especial aprovechamiento y/o pleno contacto con la naturaleza., c) Que posea una determinada extensión superficial acondicionada para la construcción de unidades habitacionales de uso residencial, d)Que el área común de equipamiento y/o esparcimiento y el área de unidades habitacionales deben guardar una mutua e indisoluble relación funcional y jurídica, que las convierta en un todo inescindible. (...)". Esta Ley, además de especificidades relacionadas con la administración y reglamentación, establece que las personas físicas o jurídicas, públicas o privadas, deberán tramitar la pre factibilidad municipal y la posterior convalidación Técnica del Municipio en donde se ubica y/o de los organismos provinciales competentes para las factibilidades de infraestructura y servicios que corresponda.

El área analizada corresponde a las jurisdicciones de los Municipios de Corrientes y Santa Ana de los Guácaras, con ejidos municipales colindantes. Ambos Municipios cuentan con Cartas Orgánicas, en el caso de Corrientes (Carta Orgánica Municipal de la Ciudad de Corrientes, Reforma 2013) establece entre los objetivos de la Políticas Municipales en el Art.14, regular el ordenamiento territorial y el crecimiento armónico de la ciudad considerando las características bio-físicas, garantizando el uso racional y eficiente socialmente justo y ambientalmente equilibrado del territorio y propender a los fines sociales de la actividad urbanística mediante la intervención en el mercado de tierras.

Por otra parte, el Municipio de Santa Ana en su Carta Orgánica (Carta Orgánica Municipalidad de Santa Ana de los Guácaras, 2012), establece potestades del Municipio en relación con la planificación de su territorio y en el Art. 18 se establece la necesidad del uso racional de los recursos naturales, respetando el principio de utilidad pública y la función social de la propiedad. Entre los objetivos de la planificación estratégica en el Art. 50 y el Art. 52, se propone lograr un Municipio funcionalmente equilibrado, socialmente equitativo y con una participación efectiva de sus

Publicado en formato digital: Arq. Silvina López; Ing. Guillermo Antonio Arce; Prof. Mgter. Jorge Alfredo Alberto. GEOINDICADORES APLICADOS AL ESTUDIO DE IMPACTOS AMBIENTALES EN EL ÁREA PERIURBANA DE LA CIUDAD DE CORRIENTES. Revista Geográfica Digital. IGUNNE. Facultad de Humanidades. UNNE. Año 12. N No 23. Enero - Junio 2015. ISSN 1668 - 5180. Resistencia, Chaco. En: http://hum.unne.edu.ar/revistas/geoweb/default.htm 
vecinos, integrado y articulado con su entorno urbano, suburbano y rural, así como proyectar el desarrollo urbano atendiendo a la calidad de vida de los habitantes, evitando la marginación. Finalmente la Carta Orgánica establece que "el planeamiento se extenderá al territorio rural, especialmente orientado a las políticas de preservación del suelo".

En ejercicio de su autonomía, cada Municipio debe elaborar los planes y aprobar la normativa por medio de sus Consejos Deliberantes, dictando Ordenanzas, que son la herramienta de regulación en materia de ordenamiento territorial.

En el caso del Municipio de Corrientes, el Código de Planeamiento Urbano (CPU, Ordenanza No 1071 y modificatorias) zonifica el territorio del mismo, tanto el área urbana como rural y regula su uso y forma de ocupación.

Dentro del área analizada, además de distritos residenciales extra-urbanos (R4) y de equipamientos especiales y generales de la ciudad (E2, Ee, Eg), identifica una Zona de Interés Paisajístico (Z.I.P.): "zona del área rural- urbana con características paisajísticas relevantes a preservar y/o promover su desarrollo" (Texto según Ordenanza № 5050) y una Zona de Promoción Agropecuaria y Protección Ambiental (ZP-PA): "zona del área rural con características particulares por tratarse de lomas arenosas cuyas cotas oscilan entre 60 y 70 metros sobre el nivel del mar con gran número de lagunas de agua dulce, a preservar y/o promover el uso agrícola - pecuario garantizando el mantenimiento de sus condiciones ambientales y un desarrollo sustentable." (Texto según Ordenanza № 5050) (Fig. 2).

En la primera (Z.I.P), el CPU establece que "toda acción a llevar a cabo en esta área tendrá en cuenta la preservación de las condiciones naturales de la misma", y permite como usos del suelo "clubes de campo, conjuntos integrales para residencias de fin de semana, y cementerios parque" fijando superficie mínima de parcela de $2.500 \mathrm{~m} 2$ y frente mínimo de $25 \mathrm{~m}$. En la segunda (ZP-PA), se prevé la consolidación de su perfil productivo promoviendo el uso intensivo del suelo con actividades de tipo agrícola - pecuario de cría, y actividades de procesamiento afín a las mismas, quedando prohibido "efectuar operaciones extractivas de tierra, como así también actividades que modifiquen las condiciones naturales de drenaje y los recursos del suelo."

La mayoría de los desarrollos relevados se encuentran dentro del área permitida (Z.I.P), pero aparecen otros en la zona ZP-PA donde no está permitido ese uso del suelo (Fig. 2). Tampoco se respetan las superficies de parcela mínima fijada en el área permitida, ya que se han relevado lotes de superficie inferior.

Por otra parte, la Municipalidad de Corrientes se adhirió a la Ley provincial de barrios cerrados (por Ordenanza 4024), pero no cuenta con normativa específica para regular este tipo de proyectos, excepto lo reglamentado para su localización y superficie mínima de parcela en la zona ZIP como se vio anteriormente. En cuanto al Municipio de Santa Ana, tiene ordenanzas que regulan el área urbana de la localidad, no así normativa específica que regule la ocupación de todo el territorio bajo su jurisdicción.

En síntesis, los diferentes niveles del Estado son coincidentes en cuanto a los principios generales y cuentan con marcos normativos para regular los proyectos inmobiliarios que se analizan, pero carecen de normas específicas que hagan operativo ese control.

Si bien está definida la concurrencia de los distintos organismos responsables, no se establecen las formas de articulación, ni los procedimientos para la intervención en los procesos de gestión y aprobación de este tipo de proyectos.

Finalmente, no están regulados el tamaño mínimo y máximo del predio que puede ser afectado a este tipo de urbanización, ni las características de los límites, ni los requerimientos en cuanto a la materialización de camino público, o la accesibilidad a los espejos de agua, etc., ninguna de las condiciones que sería necesario verificar para lograr el cumplimiento de los objetivos planteados tanto en las Cartas Orgánicas de los municipios, como en el CPU de Corrientes.

Publicado en formato digital: Arq. Silvina López; Ing. Guillermo Antonio Arce; Prof. Mgter. Jorge Alfredo Alberto. GEOINDICADORES APLICADOS AL ESTUDIO DE IMPACTOS AMBIENTALES EN EL ÁREA PERIURBANA DE LA CIUDAD DE CORRIENTES. Revista Geográfica Digital. IGUNNE. Facultad de Humanidades. UNNE. Año 12. No 23. Enero - Junio 2015. ISSN 1668 - 5180. Resistencia, Chaco. En: http://hum.unne.edu.ar/revistas/geoweb/default.htm 


\section{Consideraciones Finales}

La escala de la ciudad que se analiza, hace más evidente el impacto del fenómeno que se está produciendo, en el que el desplazamiento de población de nivel socioeconómico medio-alto al área periurbana y rural está provocando el consumo de tierras productivas que abastecen a la ciudad, y por otra parte, la subutilización de áreas urbanas tradicionalmente ocupadas por esos estratos sociales. En relación con la presunta autonomía de estos enclaves respecto de las infraestructuras y servicios de la ciudad, no es tal, en tanto se están generando diversas situaciones de impacto ambiental.

El análisis evidencia la baja integración entre lo natural y social, ya que no se tienen en cuenta los diversos tipos de actores sociales, los objetivos sectoriales, el efecto de intervenciones para obtener beneficios a corto plazo, la incidencia que esto tiene sobre los habitantes del área, la repartición de los beneficios del uso de los recursos, etc.

El fenómeno aparece como resultado del funcionamiento del mercado inmobiliario en el que la especulación con suelos se propaga desde el centro y los barrios de alta renta a la periferia y la rentabilidad del suelo para usos residenciales presiona sobre el uso productivo modificando el uso de suelo a residencial. En este proceso tiene una gran influencia la valorización de la propiedad inmueble.

Por otra parte, en relación con la escala y evolución, se plantea que los desarrollos inmobiliarios residenciales iniciales de pequeña escala, con efectos negativos menores de la segregación, de continuar el proceso por agregación de proyectos se intensificará la segregación, con efectos negativos especialmente para los de nivel socioeconómico más bajo. De la misma manera, la agregación de desarrollos residenciales cerrados, aumentará cada vez más la superficie de espacio privatizado, haciendo cada vez más difícil el acceso y uso de bienes públicos, como espejos de agua, paisajes y otros recursos, del resto de la población.

En cuanto a la intervención del Estado, el accionar en la gestión del suelo y políticas urbanas está respaldado en un marco legal de regulación y control relacionados con la planificación del territorio, pero se evidencian serios inconvenientes de articulación y acción política coordinada entre los gobiernos municipales y provinciales, así como la ausencia de instrumentos que hagan operativos los procesos de intervención decidida en la regulación y el control social del suelo y la propiedad.

La falta de políticas de producción de suelo urbano, deja a cargo del estado provincial y/o municipal toda la carga de la construcción de infraestructura y provisión de servicios, mientras que las obligaciones de los propietarios y emprendedores son pocas, y los beneficios son recogidos por los actores económicos del mercado inmobiliario.

El control de los procesos de incorporación de suelo al área urbana y de recuperación de plusvalías es indispensable si se pretende evitar el efecto negativo que tiene el funcionamiento de los mercados de suelo en materia de segregación residencial.

La política de control de procesos urbanos y usos del suelo, constituye una potestad indelegable del Estado, que éste debe utilizar para recuperar para la comunidad plusvalías originadas en los esfuerzos privados y públicos, que esa misma comunidad realiza. 


\section{Bibliografía}

- Alberto, Jorge A. (2012). "Papel de los geoindicadores en el análisis espacial. Una herramienta de apoyo a la ciencia geográfica". Revista Geográfica Digital. IGUNNE. Facultad de Humanidades. UNNE. Año 9. № 17. Resistencia.

- Arce, Guillermo, Lopez, Silvina Y Alberto, Jorge (2013). "Propuesta de geoindicadores en desarrollo sostenible en espacios periurbanos. Estudio de caso en la ciudad de Corrientes". Anales del XXXIII Encuentro de Geohistoria Regional pag. 251 a 268. Universidad Nacional de Formosa. Formosa, septiembre 2013. (CD ROOM) ISBN 978-987-1604-21-0. EDUNaF.

- Lopez, Silvina, Arce, Guillermo, Alberto, Jorge (2014). "Indicadores de desarrollo sostenible para espacios sujetos a la presión del crecimiento urbano. Santa Ana de los Guácaras. Corrientes". XXXIV de Geohistoria Regional. Resistencia, 26 de septiembre de 2014. En prensa.

- Alberto, Jorge, Lopez, Silvina, Arce, Guillermo (2014). "Uso del suelo en espacios rurales sujetos a la presión del crecimiento urbano. Estudio de caso: Pje. Peruchena-Sabadini, Colonia Benitez. Chaco". XXXIV de Geohistoria Regional. Resistencia, 26 de septiembre de 2014. En prensa.

- B.I.D. (1998). "La ciudad en el siglo XXI. Experiencias exitosas en gestión del desarrollo urbano en América Latina". Eduardo Rojas y Robert Daughters editores.

- Buzai, G. (2003). "Mapas sociales urbanos". $1^{\circ}$ ed. Buenos Aires, Lugar.

- Caldeira, T. (2000). City of Walls. Crime, Segregation and Citizenship in Sao Paulo. Los Angeles, London: University of California Press.

- Capel, H. (1994). "Las periferias urbanas y la geografía". Reflexiones para arquitectos. Barcelona: En Capel H. La geografía hoy. Textos, historia y documentación, Materiales de trabajo intelectual. Barcelona: Anthropos No 43.

- Coltrinari, L. (2001). "Geoindicadores de cambios globales rápidos en los trópicos húmedos". En Encuentro de Geógrafos de América Latina, Universidad de Chile, 8.. Santiago (Chile) en <http://geodados.pg.utfpr.edu.br/busca/detalhe.php?id=23145>

- Constantini, E. (1999). “...el rechazo a la ciudad?”. en Revista a/mbiente № 79. Fundación CEPA.

- Folch, R., y otros (1999). "El debate:¿ciudad cerrada o ciudad abierta?". en Revista a/mbiente $N^{0} 79$. Fundación CEPA.

- Janoschka, M. (2002). “Urbanizaciones privadas en Buenos Aires. ¿hacia un nuevo modelo de ciudad latinoamericana?". en: Latinoamérica, países abiertos ciudades cerradas. Universidad de Guadalajara. UNESCO.

- Jobert, B. (2004). “Estado, Sociedad, Políticas Públicas”. Santiago de Chile. LOM

Publicado en formato digital: Arq. Silvina López; Ing. Guillermo Antonio Arce; Prof. Mgter. Jorge Alfredo Alberto. GEOINDICADORES APLICADOS AL ESTUDIO DE IMPACTOS AMBIENTALES EN EL ÁREA PERIURBANA DE LA CIUDAD DE CORRIENTES. Revista Geográfica Digital. IGUNNE. Facultad de Humanidades. UNNE. Año 12. No 23. Enero - Junio 2015. ISSN 1668 - 5180. Resistencia, Chaco. En: http://hum.unne.edu.ar/revistas/geoweb/default.htm 
Revista Geográfica Digital. IGUNNE. Facultad de Humanidades. UNNE. Año 12. № 23. Enero - Junio 2015. ISSN 1668-5180 Resistencia, Chaco

- Lineu Castell. (1992). en "La urbanidad detrás de rejas". Revista a/mbiente №72. Fundación CEPA.

- Puebla, G. (2004). "Aproximaciones al concepto de periurbano", mimeo, Caseros: Cátedra de Gestión Local, Universidad Nacional de Tres de Febrero.

- Roccatagliata, J. (1999). "Gestión y Organización Ambiental del territorio". Doc.M4. Maestría en Gestión Ambiental.

- Sabatini, F. (2003). "La Segregación Social del Espacio en las Ciudades de América Latina". Washington D.C.: Banco Interamericano de Desarrollo.

- Sabatini, F. \& Cáceres, G. (2004). "Los Barrios Cerrados y la Ruptura del Patrón tradicional de Segregación en las Ciudades Latinoamericanas: el caso de Santiago de Chile". en G. Cáceres y F. Sabatini (Eds.). Barrios Cerrados en Santiago de Chile. Entre la Exclusión y la Integración Residencial. Santiago: Lincoln Institute of Land Policy, Pontificia Universidad Católica de Chile.

- Sánchez Negrette, A. (1995). "Tren "El Económico" su gravitación en los poblados correntinos". Corrientes.

- Segré, R. (1985). "Historia de la Arquitectura y el Urbanismo". Instituto de estudios de administración local.

- Solinis, G. (2002). "Latinoamérica: Países Abiertos, Ciudades Cerradas. Introducción". En L.F. Cabrales (Ed.). México: Universidad de Guadalajara, UNESCO.

- Subirats, J. (2001). "El análisis de las políticas públicas". Debate: Políticas Públicas y Sociedad Civil en cgpp.app.jalisco.gob.mx .

\section{Antecedentes y trabajos consultados}

- Carta Orgánica Municipalidad de Santa Ana de los Guácaras. 2012. Boletín Oficial № 26.312

- Carta Orgánica Municipal de la Ciudad de Corrientes. Reforma 2013

- Censo Nacional de Población, Hogares y Vivienda. Argentina. 2010

- Código de aguas de la Provincia de Corrientes. Decreto Ley 191/01. Digesto Hídrico de la RA en www.digestohídrico.org.ar .

- Código de Planeamiento Urbano de la ciudad de Corrientes. Ordenanza No1071 y modificatorias.

- Constitución de la Provincia de Corrientes. Reforma 2007.

- Ley Provincial No 5405. 1999. Reglamentaria de Clubes de Campos y/o Country

- Plan estratégico territorial Avance II: Argentina Urbana. 2011. Ministerio de Planificación Federal, Inversión Pública y Servicios.

- Programa de planificación de municipios correntinos. 2003. "Planificación estratégica urbanoambiental. Diagnóstico de la localidad de Santa Ana de los Guácaras". IN.VI.CO.

- SIG de la Municipalidad de Corrientes en http://gis.ciudaddecorrientes.gob.arl. 2014

Publicado en formato digital: Arq. Silvina López; Ing. Guillermo Antonio Arce; Prof. Mgter. Jorge Alfredo Alberto. GEOINDICADORES APLICADOS AL ESTUDIO DE IMPACTOS AMBIENTALES EN EL ÁREA PERIURBANA DE LA CIUDAD DE CORRIENTES. Revista Geográfica Digital. IGUNNE. Facultad de Humanidades. UNNE. Año 12. N No 23. Enero - Junio 2015. ISSN 1668 - 5180. Resistencia, Chaco. En: http://hum.unne.edu.ar/revistas/geoweb/default.htm 